\begin{abstract}
Ministério da Educação
Secretaria de Articulação com os Sistemas de Ensino - SASE/MEC

Diretoria de Articulação com os Sistemas de Ensino
\end{abstract}

O Sistema Nacional de Educação, previsto no Artigo 214 da Constituição Federal de 1988, deve ser instituído no prazo de dois anos contados a partir da publicação da Lei 13.005/2014 (Artigo 13). Dando sequência à sua agenda instituinte, apresentamos o texto abaixo, elaborado pelo Ministério da Educação (MEC) com a contribuição qualificada de especialistas ${ }^{1}$. Temos a expectativa de que o documento se desdobre em discussões por todo o país e receba contribuições para a construção de uma proposta coletiva que encontre eco no Congresso Nacional.

\title{
INSTITUIR UM SISTEMA NACIONAL DE EDUCAÇÃO: AGENDA OBRIGATÓRIA PARA O PAÍS
}

A educação é um direito social inalienável definido pela Constituição Federal de 1988 para cada cidadão brasileiro. Essa inscrição resultou, ao longo dos anos, em vários instrumentos legais de grande impacto como por exemplo a LDB, que redesenhou a educação nacional no pós-ditadura; o FUNDEF e, depois, o FUNDEB, que promoveram inegável equalização de oportunidades educacionais, além de muitos outros dispositivos legais importantes para a política pública educacional. De forma especial, merece destaque a Emenda Constitucional 59/2009, que trouxe marcos jurídicos avançados, como a obrigatoriedade do ensino para crianças e adolescentes de 4 a 17 anos, o Plano Nacional de Educação (PNE) e a inclusão, no texto constitucional, da expressão Sistema Nacional de Educaşão (SNE).

O PNE alcançou caráter de Plano de Estado, cobrindo períodos de dez anos, com explícita vinculação de recursos para a sua execução². Um grande avanço! Um plano decenal previsto na Constituição faz com que planos de governo obrigatoriamente o tomem como referência, consolidando políticas com maior articulação federativa. Além disso, o PNE tornou-se o articulador do Sistema Nacional de Educação, mas paradoxalmente vivenciamos hoje a situação de termos um PNE em vigor (Lei 13.005/2014)

1 Texto elaborado pela SASE/MEC, com a contribuição de Carlos Augusto Abicalil (OEI), Carlos Roberto Jamil Cury (PUC/MG), Luiz Fernandes Dourado (UFG e CNE) e Romualdo Luiz Portela de Oliveira (USP).

2 estabelecimento da meta de aplicação de recursos públicos em educação como proporção do Produto Interno Bruto (PIB) 


\section{Ministério da Educação}

Secretaria de Articulação com os Sistemas de Ensino - SASE/MEC

Diretoria de Articulação com os Sistemas de Ensino

sem que o SNE a ser por ele articulado esteja ainda instituído.

A ausência de um $\mathrm{SNE}^{3}$ até os dias atuais tem resultado em graves fragilidades para a educação nacional, como a ausência de referenciais nacionais de qualidade capazes de orientar a ação supletiva para a busca da equidade, a descontinuidade de ações, a fragmentação de programas e a falta de articulação entre as esferas de governo. Esses fatores não contribuem para a superação das históricas desigualdades econômicas e sociais do país.

Os resultados pontuais também não são capazes de ajudar na superação dos significativos problemas sistêmicos, imbricados na complexidade e nas tensões próprias do contexto federativo, que dificultam a organização da educação brasileira por meio de formas de colaboração capazes de efetivamente garantir o direito constitucional. Sem o Sistema, as lacunas de acordos federativos vinculantes ${ }^{4}$, seja para a oferta da educação pelo setor público, seja para a regulação do setor privado, se concretizam na inequidade. Isso contradiz o princípio constitucional e afronta a cidadania e os direitos humanos.

Considerando a premente necessidade de aperfeiçoarmos a organização da educação nacional para que as políticas sejam mais orgânicas e capazes de assegurar o direito constitucional com equidade, é indispensável avançarmos na agenda instituinte do SNE. Sabemos que buscar consensos em torno de temas estruturantes que atendam as atuais necessidades do país exigirá grande esforço, pois a disputa política considera diferentes rotas possíveis para chegar lá. Além disso, é preciso lembrar que o Federalismo brasileiro foi conformado num contexto histórico marcado

3 Sistema Nacional de Educação entendido aqui como um aperfeiçoamento na organização da educação nacional, sustentada por um pacto federativo construído de forma democrática e inscrito em um conjunto de leis nacionais, capazes de orientar cada sistema ou rede de ensino para que o direito constitucional inalienável seja garantido, com equidade, a cada cidadão brasileiro.

4 Normas que obrigam todos os órgãos da Administração Pública e do Judiciário a atuarem conforme seus dispositivos. 


\begin{abstract}
Ministério da Educação
Secretaria de Articulação com os Sistemas de Ensino - SASE/MEC

Diretoria de Articulação com os Sistemas de Ensino
\end{abstract}

por forte pressão para fortalecer autonomias e não para criar identidade nacional.

Mas a Lei do PNE ajuda nesse desafio: define ações e estabelece prazos para diversas iniciativas que, se organizadas de maneira sistêmica, concretizarão a agenda instituinte do SNE. Assim, partimos do pressuposto de que as metas desse e dos próximos planos nacionais articularão o Sistema, mas alguns dispositivos e algumas estratégias da lei atualmente em vigor podem ajudar a formatá-lo. As disposições que merecem destaque neste sentido aparecem na Lei 13.005/2014 na seguinte sequência:

- Artigo 6o: realização de pelo menos 2 (duas) conferências nacionais de educação até o final do decênio

- Artigo 7o: criação de uma instância permanente de negociação e cooperação entre a União, os Estados, o Distrito Federal e os Municípios, e instâncias similares em cada Estado

- Artigo 8o: elaboração de planos sub nacionais consonantes ao PNE no prazo de um ano após a publicação da Lei

- Artigo 9o: aprovação de leis específicas para os sistemas de ensino, que disciplinem a gestão democrática da educação pública no prazo de 2 (dois) anos contado da publicação da Lei

- Artigo 11: instituição do sistema nacional de avaliação da educação básica (Artigo 11)

- Artigo 13: intuição do SNE em lei especifica, no prazo de dois anos após a publicação da Lei

- Estratégias 2.1, 2.2, 3.2 e 3.3: envio de proposta ao CNE de direitos e objetivos de aprendizagem e desenvolvimento que configurarão a base nacional comum curricular do ensino fundamental e médio em dois anos, com pactuaşão interfederativa para sua implantação.

- Meta 15: garantir, em regime de colaboração entre a União, os Estados, o Distrito Federal e os Municípios, no prazo de 1 (um) ano de vigência deste PNE, política nacional de formação dos profissionais da educaşão

- Estratégia 17.1: constituir, por iniciativa do Ministério da Educação, até o final do primeiro ano de vigência deste PNE, fórum permanente, com 


\section{Ministério da Educação}

Secretaria de Articulação com os Sistemas de Ensino - SASE/MEC

Diretoria de Articulação com os Sistemas de Ensino

representação da União, dos Estados, do Distrito Federal, dos Municípios e dos trabalhadores da educação, para acompanhamento da atualização progressiva do valor do piso salarial nacional para os profissionais do magistério público da educação básica.

- Meta 20: ampliação do investimento público em educação pública de forma a atingir, no minimo, o patamar de 7\% (sete por cento) do Produto Interno Bruto - PIB do País no $5^{\circ}$ (quinto) ano de vigência da Lei e, no mínimo, o equivalente a $10 \%$ (dez.por cento) do PIB ao final do decênio.

- Estratégias 20.6 e 20.7: implantação do Custo Aluno Qualidade inicial (em dois anos)

- Estratégia 20.9: regulamentação do Artigo 23 da Constituição Federal em dois anos

- Estratégia 20.10: caberá à União, na forma da lei, a complementação de recursos financeiros a todos os Estados, ao Distrito Federal e aos Municípios que não conseguirem atingir o valor do CAQi e, posteriormente, do CAQ.

Em decorrência do disposto no Artigo 13 da Lei, também se define que o sistema deve ser instituído, no prazo de dois anos, em lei específica.

Porém, entendemos que apenas uma lei não seria suficiente para tal. A proposta é que instituição do Sistema Nacional se dê por um conjunto articulado de quatro dimensões, levando a uma nova forma de organização da educação nacional: alterações na LDB; regulamentação do Artigo 23 da Constituição Federal - ou a Lei de Responsabilidade Educacional; adequação das regras de financiamento e adequação dos sistemas de ensino às novas regras nacionais.

\section{Alterações na LDB}

A educação no Brasil é nacional porque se assenta em diretrizes e bases que cobrem o conjunto dos sistemas de ensino (o federal, os estaduais, o distrital e os municipais e, no seu interior, as redes públicas e privadas que os constituem). Portanto, será imprescindível uma releitura da LDB à luz do Sistema Nacional de Educação a ser configurado.

É indispensável incluir na LDB um capítulo sobre o Sistema Nacional de 


\section{Ministério da Educação \\ Secretaria de Articulação com os Sistemas de Ensino - SASE/MEC \\ Diretoria de Articulação com os Sistemas de Ensino}

Educação ${ }^{5}$. Mas é necessário incluir também dispositivos que se caracterizem como referenciais nacionais de qualidade para:

a) uma base nacional comum ${ }^{6}$ que oriente a formação docente ${ }^{7}$ e os processos de avaliação de aprendizagem ${ }^{8}$;

b) a estrutura e o funcionamento de estabelecimentos escolares';

c) a valorização profissional e a avaliação institucional; e

d) a gestão democrática, no seu sentido amplo ${ }^{10}$, incluindo o funcionamento de conselhos, fóruns, instâncias de negociação ${ }^{11}$ e as conferências de educação ${ }^{12}$.

Um processo dialógico de construção da Base Nacional Comum a partir das Diretrizes do Conselho Nacional de Educação ${ }^{13}$, coordenado pela União, com efetivo envolvimento dos sistemas de ensino e da sociedade, ajudará a definir um ponto de equilíbrio entre orientações gerais e listas prescritivas de conteúdos e contribuirá efetivamente para que as instituições escolares construam percursos de implantação das Diretrizes como base de seu projeto curricular. Ensejará padrões nacionais de qualidade articulados à diversificação curricular, constituindo-se em unidade na diversidade e reorientando o trabalho das instituições educacionais. Propiciarão, desse modo, condições basilares para que se supere a adoção passiva de modelos prontos, ou dos chamados "sistemas apostilados".

A Base Nacional Comum, neste contexto, também se articulará à política nacional de formação dos profissionais do magistério e ao Sistema Nacional de Avaliação da Educação Básica.

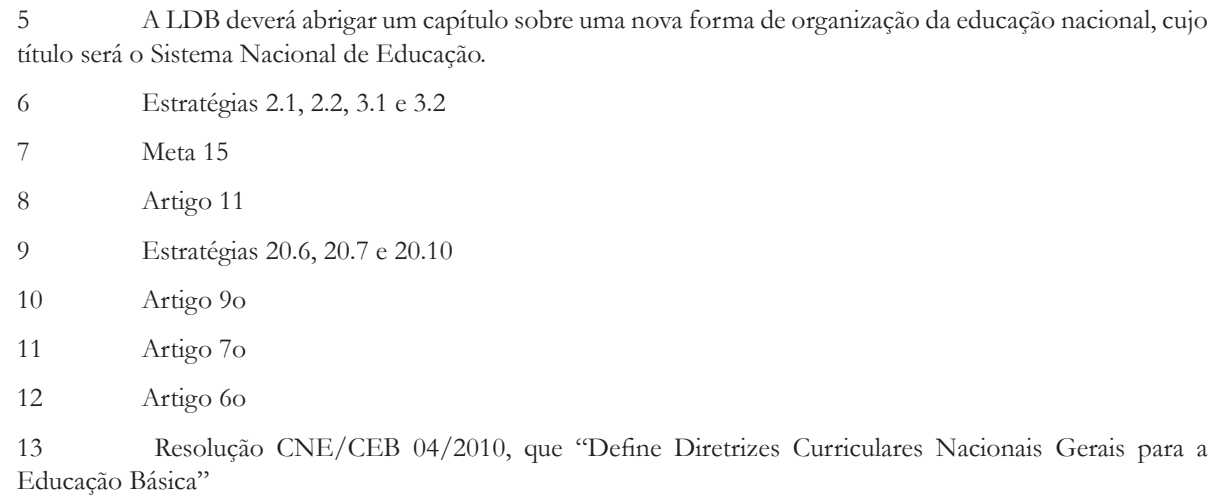
Educação Básica” 


\section{Ministério da Educação}

Secretaria de Articulação com os Sistemas de Ensino - SASE/MEC

Diretoria de Articulação com os Sistemas de Ensino

Hoje a falta de uma Base Nacional Comum inviabiliza, por um lado, orientações claras e potentes para a composição dos currículos das licenciaturas e, por outro, a regulação mais enérgica do setor privado. Para aprimorar a Política Nacional de Formação dos Profissionais do Magistério (Decreto 6.755/2009) e dos profissionais que não os do magistério (Decreto 7.415/2010) será estratégico articular os programas do MEC e construir mecanismos que fortaleçam a colaboração entre os sistemas de ensino, em um conjunto mais orgânico de ações integradas. Tais ações precisam considerar as competências e estruturas específicas das instituições, sistemas e redes de ensino, e sua necessária articulação e colaboração.

O Sistema Nacional de Avaliação da Educação Básica, por sua vez, previsto no Artigo 11 da Lei do PNE, exigirá o desenvolvimento de mecanismos permanentes de aprimoramento dos indicadores educacionais, tanto daqueles relativos ao desempenho dos estudantes quanto daqueles de avaliação institucional. Perfil do alunado e dos profissionais da educação, capacidade de oferta, infraestrutura e recursos pedagógicos disponíveis, processos de gestão, condições de trabalho, são exemplos de dimensões relevantes a serem consideradas.

Com relação à estrutura e ao funcionamento de estabelecimentos educacionais, entendemos ser necessário construir acordos em torno de referenciais de qualidade que orientem a ação supletiva da União em relação dos estados, Distrito Federal e municípios, e dos estados em relação aos municípios. Uma lista descritiva de insumos não necessariamente resulta em qualidade, mas referenciais combinados de forma sistêmica poderão fazer com que os padrões mínimos de oportunidades educacionais realmente se concretizem como direito de cada cidadão ao acessar o serviço público educacional, ou o serviço privado por ele regulado. São elementos que conformarão a identidade nacional, cujos princípios devem necessariamente compor a Lei de Diretrizes e Bases da Educação Nacional.

Para a valorização profissional, importante componente do Sistema, é imprescindível prever espaços de diálogo e de negociação, que contribuam para a melhoria da vida profissional pela via da pactuação, resultando em diretrizes nacionais de carreira e condições de trabalho.

Diretrizes nacionais de carreira, salários atrativos, condições de trabalho adequadas, processos de formação inicial e continuada e formas criteriosas de 


\section{Ministério da Educação}

Secretaria de Articulação com os Sistemas de Ensino - SASE/MEC

Diretoria de Articulação com os Sistemas de Ensino

seleção são requisitos para reconhecer a valorização dos profissionais da educação como parte integrante e articuladora do Sistema Nacional; estes aspectos não podem ser tratados de forma fragmentada. Isso não significa, necessariamente, construir uma carreira nacional padrão, nem uma carreira única para o país. Carreiras equilibradas colaboram para a atração de bons profissionais, para o cumprimento do Piso Salarial Profissional Nacional e para a valorização da profissão. A diversidade de modelos hoje existentes (elevada variação entre o maior e o menor salário, tipos diferentes de gratificações, regras muito diferenciadas de promoção) dificulta a viabilidade dos objetivos da Lei do Piso (11.738/2008).

Porém, a qualidade do Sistema, tomada como conceito polissêmico, necessariamente deve considerar o princípio constitucional da gestão democrática. Os mecanismos democráticos devem estar presentes em todas as estruturas e relações que se estabelecerem no SNE, desde a instituição educativa, com o necessário fortalecimento dos Conselhos Escolares até o órgão executivo do Município, do Estado, do Distrito Federal e da União. Tal princípio se concretizará por intermédio da instituição e fortalecimento de espaços de negociação, de participação e de controle social: comitês, comissões, conselhos, fóruns, conferências, grupos de trabalho entre outros. É importante ressaltar, nesse processo, a necessidade de se garantir os processos de efetiva participação e decisão a serem definidos nos marcos da regulamentação dos sistemas de ensino e nos projetos pedagógicos das instituições educacionais, instituindo e consolidando os mecanismos democráticos na gestão.

Com esse princípio, os espaços de normatização, negociação, pactuação, deliberação, consulta, participação, acompanhamento e controle social precisam ser fortalecidos e aperfeiçoados.

O Conselho Nacional de Educação (CNE), órgão criado por lei, deve deliberar sobre políticas educacionais e questões pedagógicas. Uma Instância Nacional Permanente de Negociação Federativa (MEC, CONSED, UNDIME), por sua vez, deve pactuar aspectos de gestão e financiamento, condições indispensáveis à qualidade pedagógica almejada. Assim, instalado esse novo espaço de diálogo no Sistema, será necessário buscar, permanentemente, coesão e harmonia entre as deliberações de uma e as da outra instância. Tal estrutura deve se repetir em cada unidade federativa, com composição bipartite, para atuação nas suas respectivas esferas de competência. 


\section{Ministério da Educação}

Secretaria de Articulação com os Sistemas de Ensino - SASE/MEC

Diretoria de Articulação com os Sistemas de Ensino

O papel normativo (das diretrizes nacionais), deliberativo (nas funções de avaliação e regulação no âmbito do sistema federal) e consultivo do CNE deve ser reforçado e sua composição deveria combinar capacidades técnicas com representação federativa. Os conselhos estaduais, no mesmo sentido, devem ter o seu papel normativo (diretrizes complementares), deliberativo (com relação aos processos de avaliação e regulação da oferta no âmbito do sistema estadual) e consultivo reforçado. Sua composição igualmente deveria refletir a combinação de capacidades técnicas com a representação mais fiel possível das diversidades regionais existentes no interior de cada Unidade da Federação.

Nesse contexto torna-se importante também reforçar a importância e o papel dos Conselhos Municipais de Educação. Naqueles Municípios que instituírem sistemas próprios, as competências normativa, deliberativa e consultiva no âmbito de seu sistema (funcionamento, credenciamento e recredenciamento de instituições, a autorização e reconhecimento de cursos, organização curricular) devem ser bem definidas e combinadas com outras atribuições eventualmente delegadas pelo Sistema Estadual. Nos Municípios integrados ao Sistema Estadual (ou que venham compor um Sistema Único), as prerrogativas previstas na legislação estadual devem ser observadas, cabendo o exercício das competências delegadas pela lei que organiza o Sistema Estadual (ou do Sistema Único).

Visando uma ação municipal mais integrada, em ambos os casos municípios com ou sem sistema próprio instituído, os Conselhos Municipais de Educação deveriam absorver as competências de acompanhamento e controle social já previstas em lei, como no caso do FUNDEB, da Alimentação e do Transporte Escolar.

Os Fóruns de Educação, previstos em todas as esferas do Sistema, devem ser fortalecidos como espaços qualificados de participação e expressão, com papel na organização das conferências e das propostas de planos de educação, monitorando e avaliando sua execução. Sua composição deveria refletir, em qualquer esfera (nacional, estadual ou municipal) ampla participação de representações sociais.

Em síntese, postulamos que o reexame da LDB será fundamental para que se explicite a natureza do SNE, explicitando a estrutura, a organização e o funcionamento do Sistema, suas finalidades, princípios e regras gerais.

Porém, tal reexame somente terá sentido se for acompanhado de normas 


\section{Ministério da Educação \\ Secretaria de Articulação com os Sistemas de Ensino - SASE/MEC \\ Diretoria de Articulação com os Sistemas de Ensino}

de cooperação federativa vinculantes, por regulamentação do inciso V do Artigo 23 da Constituição Federal, e de um conjunto orgânico de regras nacionais para o financiamento, capazes de dar sustentação ao projeto que se desenhou. Em todos os casos é fundamental reforçar os papeis de coordenação política, suplementação e redistribuição da União com relação aos Estados e Municípios e também dos Estados com relação aos seus próprios Municípios. Esses princípios darão concretude ao Regime de Colaboração previsto no Artigo 211 da Constituição Federal, proposta que detalhamos a seguir.

\section{Regulamentação do Artigo 23, ou a Lei de Responsabilidade Educacional}

Para que os referenciais nacionais de qualidade definidos na LDB sejam garantidos e a organização da educação nacional se dê em Regime de Colaboração, uma segunda iniciativa deve ser a regulamentação do inciso V do Artigo 23 da Constituição Federal ${ }^{14}$. Tal regulamentação, por força do Parágrafo Único desse Artigo, deverá fixar normas em lei complementar para a cooperação entre a União e os Estados, o Distrito Federal e os Municípios. Tal dispositivo trata das competências comuns entre os entes federativos, entre as quais encontramos:

$V$ - proporcionar os meios de acesso à cultura, à educação, à ciência, à tecnologia, à pesquisa e à inovação(redação dada pela Emenda Constitucional no 85, de 2015).

Juridicamente, competência significa a capacidade de a autoridade possuir certas atribuições, a fim de deliberar a seu respeito ${ }^{15}$. No caso deste dispositivo constitucional, trata-se de estabelecer normas de cooperação federativa capazes de concretizar a execução das competências comuns no serviço educacional, ou seja, capazes de definir claramente as responsabilidades, compartilhadas, sobre a oferta educacional e sobre sua qualidade.

Muito se tem falado sobre uma Lei de Responsabilidade Educacional. Responsabilizar é definir responsabilidades, prever as condições para o seu exercício e para o seu acompanhamento e controle. Uma Lei Complementar que

\footnotetext{
14 Estratégia 20.9

15 Araujo,G.C. Direito à educação básica: a cooperação entre os entes federados. Revista Retratos da Escola, Brasília, v. 4, n. 7, p. 231-243, jul./dez. 2010.
} 


\section{Ministério da Educação}

Secretaria de Articulação com os Sistemas de Ensino - SASE/MEC

Diretoria de Articulação com os Sistemas de Ensino

regulamente o Inciso V do Artigo 23 da Constituição será a Lei de Responsabilidade Educacional, pois tratará das normas de cooperação obrigatórias para dar sustentação à nova forma de organização da educação nacional. Tais normas devem ser regras claras de supletividade vinculadas aos referenciais de qualidade, trazendo na sua base o princípio da interdependência e da cooperação.

A possibilidade de avanço neste aspecto está na busca de acordos em torno de regras federativas que possam constituir a base do sistema a ser organizado. Regras que dirijam não apenas os processos de responsabilização - entendida como "quem faz o que", mas principalmente com quem e em que condições faz, com quais mediações de complementariedades, com quais regramentos e com quais definições de responsáveis pelas deliberações ${ }^{16}$.

Assim, por exemplo, as normas de cooperação federativa devem tornar obrigatório o funcionamento dos Conselhos de Educação e das instâncias de participação e pactuação, permitindo o funcionamento dos espaços de gestão, de elaboração de normas, de controle social e de proposição de políticas públicas com ampla participação. Nesse contexto será indispensável considerar a necessidade de resguardar as capacidades já consolidadas nos diferentes sistemas subnacionais e ao mesmo tempo identificar investimentos necessários para desenvolvê-las nas redes e sistemas em que elas ainda não estão presentes. Trata-se de um complexo desenho para a ação supletiva técnica e financeira, fundamental para que cada ente federativo possa realizar plenamente suas competências.

Em síntese, é fundamental que as normas apontem para a ação supletiva da União e dos Estados para a garantia dos referenciais nacionais de qualidade cujas bases estejam estabelecidas na LDB. É importante revermos quais são as atuais instâncias de pactuação federativa definidas em lei ou outro instrumento jurídico. Alguns exemplos são o Comitê Estratégico do PAR, criado pela Lei 12.695/2012 e a Comissão Intergovernamental do FUNDEB. Caberia rever e fortalecer alguns dos fóruns federativos existentes, desativar os que eventualmente tenham finalidades superpostas e criar novas instâncias de negociação caso se detectem lacunas, como as previstas no Artigo 7o e na Estratégia 17.1 do

16 Abicalil, C.A. O federalismo e o sistema nacional de educação: uma oportunidade fecunda. Retratos da Escola, CNTE, v. 6, n. 10, p. 21-36, jan/jul. 2012. 


\section{Ministério da Educação \\ Secretaria de Articulação com os Sistemas de Ensino - SASE/MEC \\ Diretoria de Articulação com os Sistemas de Ensino}

$\mathrm{PNE}^{17}$.

Outro aspecto estratégico e indispensável a ser considerado como norma vinculante para o SNE é a efetiva articulação entre os Planos Nacional, Estaduais e Municipais de Educação. Esse mecanismo, entendido como ação de planejamento decenal articulado ${ }^{18}$, deverá reforçar a concepção de que as metas nacionais se concretizam em cada ponto do país onde está uma pessoa a quem o direito deve ser garantido. Essa concepção deverá evitar a transposição mecânica das metas nacionais para os planos subnacionais, dada a necessidade de considerar as diferenças e desigualdades regionais. Além disso, embora não sejam planos para redes ou sistemas, e sim para territórios municipais ou estaduais, é importante articular de forma definitiva o planejamento educacional decenal a outros instrumentos de planejamento de governos, tais como os Planos Plurianuais, os Planos de Ações Articuladas (Lei 12.695/2012) e outros mecanismos de financiamento. Tais previsões de obrigatoriedade darão sustentação ao disposto no Artigo 214 da Constituição, concretizando o papel articulador do Plano Nacional de Educação.

\section{Adequação das regras de financiamento}

A terceira iniciativa dedica-se à adequação das regras do financiamento ${ }^{19}$, para que esteja de acordo com a nova organização da educação nacional.

A ação distributiva da União em matéria educacional se realiza por meio das transferências constitucionais obrigatórias, das transferências das cotas estaduais e municipais do salário educação, das disposições do artigo 60 do Ato das Disposições Constitucionais Transitórias-ADCT, das compensações financeiras resultantes de desonerações fiscais e de fomento à exportação, da

\footnotetext{
17 Artigo 7o: criação de uma instância permanente de negociação e cooperação entre a União, os Estados, o Distrito Federal e os Municípios, e instâncias similares em cada Estado;

Estratégia 17.1: constituir, por iniciativa do Ministério da Educação, até o final do primeiro ano de vigência deste PNE, fórum permanente, com representação da União, dos Estados, do Distrito Federal, dos Municípios e dos trabalhadores da educação, para acompanhamento da atualização progressiva do valor do piso salarial nacional para os profissionais do magistério público da educação básica.
} 


\section{Ministério da Educação}

Secretaria de Articulação com os Sistemas de Ensino - SASE/MEC

Diretoria de Articulação com os Sistemas de Ensino

repartição devida a Estados e Municípios de royalties por exploração de recursos naturais definidas em lei. Será necessário rever as normas do atual FUNDEB ${ }^{20}$, cuja vigência se encerra em 31 de dezembro de 2020 (Art. 48 da Lei 11.494/2007).

\section{Um novo FUNDEB, com mais equidade e efetividade do PSPN}

A forma como os recursos fiscais são repartidos entre os entes federativos, de modo que todos disponham de capacidade de financiamento compatível com suas responsabilidades, é uma questão central de qualquer regime federativo. $\mathrm{O}$ equilíbrio entre responsabilidades e recursos tem solução tão mais complexa quanto maiores forem as disparidades regionais e sociais (Resende, $2010^{21}$ ).

Um equilíbrio desta natureza depende de uma reforma tributária, que pode exigir muito mais tempo para a construção de acordos federativos do que o próprio Sistema Nacional de Educação. Neste contexto, é fundamental encontrar uma solução para o financiamento educacional, considerando que o FUNDEB termina em 2020.

O novo quadro a ser construído deve considerar uma ampliação do aporte de recursos da União que assegure maior equalização e efetividade do piso salarial (Lei 11.738/2008).

Portanto, além do aumento de recursos já previsto na Lei do PNE, para assegurar maior equalização, o Valor Aluno Ano (VAA) deverá vincular-se a referenciais nacionais de qualidade a serem amplamente pactuados, com necessária alteração dos fatores de ponderação por etapas e modalidades da educação básica. O VAA deve refletir o conceito de Custo Aluno Qualidade (CAQ), permitindo uma maior responsabilização dos dirigentes na promoção de padrões nacionais básicos de oferta. Nesse contexto se define também a função supletiva, entendida como um meio pelo qual a União, à vista de uma incapacidade justificada de o ente federado dar conta de um padrão mínimo de qualidade, subsidia, provisoriamente, aquele ente em termos financeiros ${ }^{22}$. O mesmo se pode dizer do Estado em

\footnotetext{
$20 \quad$ Lei $11.494 / 2007$

21 Resende, F. Federalismo fiscal: em busca de um novo modelo. In: Oliveira, R.P.; Santana, W. (orgs). Educação e Federalismo no Brasil: combater as desigualdades, garantir a diversidade. Brasília, DF: UNESCO, 2010. p. 71-88.

22 A função supletiva também pode ser do direito, significando o estabelecimento de uma norma quando, em face de casos concretos, tem-se a carência de uma regra específica.
} 
Ministério da Educação

Secretaria de Articulação com os Sistemas de Ensino - SASE/MEC

Diretoria de Articulação com os Sistemas de Ensino

relação aos Municípios, considerada a real situação de cada qual.

Uma possível complementação financeira da Uniãopara a complementação do Piso Salarial Profissional Nacional deverá condicionar-se a um conjunto de regras e contrapartidas dos entes federados, como a comprovação da insuficiência financeira e a demonstração do esforço fiscal.

Além destes aspectos, a complementação de salários dos profissionais da educação básica deve articular três aspectos ao longo do tempo: melhoria da gestão do sistema de ensino, plano de carreira em conformidade com o disposto no PNE e esforço do ente federativo para o aumento de recursos para a educação, como por exemplo a regulamentação da lei dos royalties priorizando essa política pública.

É importante observar que a necessidade de ampliação do aporte da União para a equalização no FUNDEB pode implicar em redução do financiamento de programas e transferências voluntárias. Nesse caso, será importante criar mecanismos para continuamente buscar equilíbrio entre programas focalizados (para a superação de problemas específicos ou localizados) e programas universais, procurando evitar que programas focalizados resultem em privilégios e que programas universais cristalizem as desigualdades.

Nesse aspecto, o Plano de Ações Articuladas (PAR) pode assumir papel central como instrumento de planejamento e pactuação das esferas de governo, permitindo o alcance de resultados não restritos apenas às redes de ensino.

Tais resultados devem concretizar ações articuladas no território, entendido como lugar onde vive o sujeito a quem o direito educacional deve ser garantido. Esse cenário tem como condição o planejamento integrado, referenciado pelo Plano Nacional de Educação e pelos planos subnacionais aprovados em consonância com seus dispositivos.

A vinculação do Valor Aluno Ano (VAA) a referenciais nacionais de qualidade a serem pactuados, cerne da definição do Custo Aluno Qualidade e referencial para ações suplementares do PAR, merecerá uma agenda específica de aprofundamento de aspectos técnicos, financeiros e conceituais.

Por fim, cabe ressaltar que os recursos derivados da exploração de petróleo e gás devem ser utilizados para compor o conjunto de esforços para viabilizar o padrão nacional de qualidade, ou o alcance de igualdade de oportunidades educacionais básicas. Entretanto, por serem recursos não renováveis, à sua 
destinação não se deve vincular qualquer mecanismo de financiamento que comprometa a sustentabilidade do Sistema.

\section{Adequação dos sistemas de ensino às novas regras nacionais}

As três dinâmicas apresentadas acima deverão resultar no que se pode chamar de descentralização qualificada ${ }^{23}$, marca de um Sistema Nacional de Educação cuja missão é a oferta educacional que equilibra qualidade com equidade, identidade nacional com identidade local. Equações como essas dependem de acordos complexos e contínuos em meio à disputa federativa, sem os quais não será possível assegurar a garantia dos direitos constitucionais.

Não é simples criar acordos sucessivos em torno de referenciais de qualidade que direcionem as normas para a ação distributiva e supletiva que deem sustentação a estes referenciais. Neste campo está o conceito da cooperação, que se diferencia constitucionalmente do conceito de colaboraşão.

Do ponto de vista semântico, poder-se-ia ponderar que os termos 'colaboração' e 'cooperação' possuem rigorosamente a mesma significação. Porém, do ponto de vista constitucional, há que distinguir o sentido. Tal distinção se dá, essencialmente, pelo lugar constitucional que ocupam: no artigo 23, referindo-se exclusivamente à relação interfederativa, entre os entes federados, alcançando todas as estruturas do Poder Público em sentido restrito, requerendo a regulação das normas de cooperação. Nas disposições em que a colaboração se apresenta, expressamente, a relação se dá entre sistemas de educação, cujas instituições públicas são partes, os entes federados possuem competências prioritárias especificas, organizam suas redes próprias, e a que todas as instituições educacionais privadas (em sua multiplicidade de formas juridicas admitidas em lei) estão vinculadas. Essa complexa relação entre sistemas de educação, por outro lado, gera formas distintas de relação institucional, ora por convênios, ora por adesão a programas, ora por pactos ou acordos, ora por determinação legal. As variadas formas são atinentes à enorme diversidade de situações a serem resolvidas em regime de colaboração ${ }^{24}$.

Portanto, entendemos que quando as regras de cooperação estiverem postas com caráter vinculante, restará colocá-las em prática. Para tanto, o caminho

\footnotetext{
23 Dourado,L.F. Sistema Nacional de Educação, Federalismo e os obstáculos ao direito à Educação Básica. Educação \& Sociedade, vol. 34:124, 2013, pp. 761-785.

24 Abicalil, C.A. O Plano Nacional de Educação e o regime de colaboração na educação - versão estendida e atualizada do artigo para a Revista Retratos da Escola/CNTE. Portal PNE(pne.mec.gov.br/), acesso em 24 de março de 2015.
} 


\title{
Ministério da Educação \\ Secretaria de Articulação com os Sistemas de Ensino - SASE/MEC \\ Diretoria de Articulação com os Sistemas de Ensino
}

constitucional é o Regime de Colaboração, expresso no Artigo 211:

\begin{abstract}
Art. 211. A União, os Estados, o Distrito Federal e os Municípios organizarãa em regime de colaboração seus sistemas de ensino.

$\int 4^{\circ} \mathrm{Na}$ organização de seus sistemas de ensino, a União, os Estados, o Distrito Federal e os Municípios definirão formas de colaboração, de modo a assegurar a universalização do ensino obrigatório. (Redação dada pela Emenda Constitucional n ${ }^{\circ}$ 59, de 2009)
\end{abstract}

Neste contexto, normas de cooperação vinculantes orientarão a ação dos entes federativos. Mas para dar conta delas, União, estados, Distrito Federal e municípios precisarão organizar seus sistemas de ensino, de acordo com as novas regras nacionais vigentes.

Um sistema de ensino se organiza por Lei e há um detalhe importante: a Constituição diz como isto deve acontecer. Ao organizarem seus sistemas de ensino, a União (e seu sistema federal), os estados (e seus sistemas estaduais) e municípios (e seus sistemas municipais, caso optem por instituí-los) devem cumprir o preceito constitucional estabelecido no Artigo 211: deverão farêe-lo em Regime de Colaboração. Portanto, nas leis que instituem os sistemas, os entes federativos deverão deixar claro como se relacionarão com os demais entes federativos.

Cada lei estadual deverá deixar clara sua relação com os municípios daquela Unidade da Federação, seja com aqueles que instituíram seu próprio sistema, seja com aqueles que optaram por permanecerem vinculados ao sistema estadual. O Regime de Colaboração, portanto, é a expressão e a forma de organização dos sistemas de ensino por meio de relações de colaboração, garantindo o cumprimento das responsabilidades definidas nas normas de cooperação e nas novas regras de financiamento, todas direcionadas pelos referenciais nacionais de qualidade expressos na LDB.

Portanto, se as normas de cooperação estiverem definidas ${ }^{25}$, todas as leis de sistema (federal, estaduais e municipais) deverão ser consonantes às regras nacionais vinculantes. Em outras palavras: não poderá mais haver maior ou menor disposição de um secretário para realizar ou não realizar determinada ação constitutiva de norma vinculante. Seu sistema de ensino deve estar organizado para isto, com todas as necessárias condições para tal. 


\section{Ministério da Educação}

Secretaria de Articulação com os Sistemas de Ensino - SASE/MEC

Diretoria de Articulação com os Sistemas de Ensino

Assim, o Regime de Colaboração é um conceito, um princípio, que deverá orientar as leis que instituem os sistemas de ensino nacional, estaduais (obrigatórios) e municipais (facultativos $-\mathrm{LDB}$ artigo 10). Para que o sistema nacional se efetive, as leis que o instituirão deverão determinar que os entes federativos, ao organizarem seus próprios sistemas de ensino, o façam por intermédio de leis vinculadas às leis do $\mathrm{SNE}$, sempre prevendo as formas de colaboração necessárias para que os pactos federativos se concretizem na prática. Será por intermédio de formas características de colaboração, em cada Unidade Federativa (estados e DF), incluindo o papel da União, que se garantirá diversidade na unidade do sistema nacional.

Por essa razão entendemos que o regime de colaboração, em si, não precisa ser regulamentado. Ele é o princípio que deve estar presente na organização dos sistemas de ensino, ou seja, nas suas leis instituidoras. Será necessário um grande esforço nacional de organização sistêmica, que certamente exigirá apoio técnico do Ministério da Educação.

Talvez em junho de 2016 ainda não tenhamos todas as quatro dimensões de trabalho finalizadas, especialmente a adequação dos sistemas subnacionais. Porém, se construirmos acordos nacionais em torno das alterações da LDB, da regulamentação do Artigo 23 (ou Lei de Responsabilidade Educacional) e das adequações dos mecanismos de financiamento vinculados aos referenciais nacionais de qualidade, muito avançaremos no esforço nacional necessário para a organização dos sistemas federal, estaduais e municipais em Regime de Colaboração, concretizando o SNE. 
Ministério da Educação

Secretaria de Articulação com os Sistemas de Ensino - SASE/MEC

Diretoria de Articulação com os Sistemas de Ensino

\section{Uma agenda}

\begin{tabular}{|c|c|c|}
\hline \multirow{3}{*}{2015} & julho e agosto & $\begin{array}{l}\text { - apresentação do presente texto pelo MEC; } \\
\text { • elaboração de uma proposição sobre a Base } \\
\text { Nacional Comum e CAQi/CAQ } \\
\text { • início dos debates nacionais }\end{array}$ \\
\hline & setembro & $\begin{array}{l}\text { - sistematização de primeiras contribuições para } \\
\text { este documento e divulgação dos demais (BNC, } \\
\text { CAQi/CAQ) }\end{array}$ \\
\hline & $\begin{array}{c}\text { setembro } \\
\text { a dezembro }\end{array}$ & $\begin{array}{l}\text { - amplo debate nacional sobre todos os documentos } \\
\text { apresentados, com recebimento de contribuições de } \\
\text { entidades nacionais }\end{array}$ \\
\hline \multirow{3}{*}{2016} & $\begin{array}{c}\text { janeiro } \\
\text { e fevereiro }\end{array}$ & $\begin{array}{c}\text { - sistematização das contribuições recebidas e } \\
\text { distribuição dos documentos sistematizados } \\
\text { • elaboração de projetos de leis e documentos ao } \\
\text { CNE }\end{array}$ \\
\hline & $\begin{array}{l}\text { março } \\
\text { a } \\
\text { junho }\end{array}$ & $\begin{array}{c}\text { - diálogo com conselheiros e parlamentares, } \\
\text { envolvendo Secretarias, Conselhos e Fóruns } \\
\text { Estaduais e Municipais de Educação } \\
\text { • tramitação dos projetos }\end{array}$ \\
\hline & $\begin{array}{l}\text { julho } \\
\text { a } \\
\text { dezembro }\end{array}$ & $\begin{array}{l}\text { - estruturação de uma rede de assistência técnica } \\
\text { para adequação das leis que organizam os sistemas } \\
\text { estaduais e municipais de ensino }\end{array}$ \\
\hline
\end{tabular}




\section{INSTRUÇÕES AOS COLABORADORES}

A Revista Brasileira de Política e Administração da Educação aceita para publicação trabalhos inéditos de autores nacionais e estrangeiros, em língua portuguesa ou espanhola. A editoria estimula e agradece antecipadamente o envio de artigos, colaborações e material para qualquer de suas seções. Os originais devem versar sobre temas pertinentes à política e à administração da educação em geral, seja sobre políticas públicas e institucionais de educação, planejamento da educação, gestão de sistemas, instituições e processos educacionais, e avaliação de políticas educacionais ou de instituições educativas.Os trabalhos devem ser remetidos à editoria da RBPAE e serão recebidos com o entendimento de que a ANPAE terá o direito de publica-los com exclusividade. Enquadrando-se no escopo e padrões editoriais da revista, serão encaminhados a consultores editoriais para avaliação. Estes manifestarão à editoria sua apreciação sobre a qualidade e pertinência da publicação, recomendações ou solicitações de atualização ou modificação dos artigos. Os consultores editoriais não terão conhecimento do nome dos autores dos textos submetidos à sua avaliação, nem os nomes dos avaliadores serão informados aos autores (blind review). Para serem publicados, os originais poderão sofrer alterações de natureza editorial.

\section{Orientação para o envio de artigos e documentos}

Os originais devem ser digitados com espaço 1,5 entre linhas. Os textos devem ser acompanhados de resumos com, no máximo, 10 linhas, em português, em inglês e em espanhol; e de, no máximo, cinco palavras-chave. As notas devem ser numeradas, sintéticas e apresentadas como notas de pé de página fonte tamanho 10. As referências devem ser indicadas no fim do artigo, e obedecer aos seguintes formatos básicos:

1. Livro: SOBRENOME, Prenome do autor. Título (em negrito) e subtítulo, se houver, separados por :. Edição (indicar só se não for a primeira, antes da abreviatura ed.). Local de publicação: editora, ano de publicação. Número de página (indicar apenas se necessário, antes de p.) Exemplo: TEIXEIRA, Anísio. Educação no Brasil. 2. ed. São Paulo: Companhia Editora Nacional, 1976.

2. Artigo de revista impressa: SOBRENOME, Prenome do autor. Título do artigo. Nome do periódico (em negrito), local de publicação, volume (indicar depois de v.), número do fascículo (indicar depois de n.), número das páginas inicial e final (indicar depois de p.), mês e ano de publicação.

Exemplo: TEIXEIRA, Anísio. Natureza e Função da Administração Escolar. Revista Brasileira de Política e Administração da Educação, Rio de Janeiro, v. 13, n. 2, p. 273-278, jul./dez. 1997. 
3. Artigo de revista eletrônica: SOBRENOME, Prenome do autor. Título do artigo. Nome do periódico (em negrito), local de publicação, volume (indicar depois de v.), número do fascículo (indicar depois de n.), número das páginas inicial e final (indicar depois de p.), mês e ano de publicação. Disponível em: <endereço eletrônico>. Acesso em: dia mês (abreviado) e ano.

Exemplo: TEIXEIRA, Anísio. Natureza e Função da Administração Escolar. Revista Brasileira de Política e Administração da Educação, Rio de Janeiro, v. 13, n. 2, p. 273-278, jul./dez. 1997. Disponível em: <http://www.anpae.org.br/anpae/ publicacoes/revistarbpae.html>. Acesso em: 13 ago. 2006.

As tabelas, gráficos, ilustrações e outras inserções devem ser acompanhadas dos respectivos títulos e legendas, tudo conforme as normas oficiais atuais. Solicita-se que venham separados do texto, com a indicação das localizações desejáveis, em cada caso, para efeito de publicação.

Junto com o material enviado, o autor deve encaminhar as seguintes informações (que serão publicadas): nome, cargo ou função atual, instituição a que está vinculado, titulação acadêmica e e-mail para contato.

Adicionalmente, para correspondência da editoria, solicita-se endereço e telefone.

Endereço para envio de artigos e correspondência

Os artigos devem ser encaminhados diretamente à editoria da RBPAE, por meio do e-mail: anpaerevista@anpae.org.br 